\title{
Resiliência e Desenvolvimento Infantil de Crianças que Cuidam de Crianças: Uma Visão em Perspectiva
}

\author{
Michele Poletto ${ }^{1}$ \\ Tânia Maria Cemin Wagner \\ Universidade de Caxias do Sul \\ Sílvia Helena Koller \\ Universidade Federal do Rio Grande do Sul
}

\begin{abstract}
RESUMO - O presente estudo teve como objetivo investigar como meninas em situação de risco estão lidando com a situação de risco de se responsabilizar por irmãos menores e pelos cuidados da casa. Quatro meninas com idades entre oito e 12 anos foram entrevistadas. As informações coletadas foram submetidas ao método de análise qualitativa lefevriano. Os resultados revelaram que as situações e os riscos a que as meninas estão submetidas deflagram o uso da capacidade de resiliência, demonstrando que conseguem utilizar diferentes recursos de modo a enfrentar e superar seus problemas e dificuldades.
\end{abstract}

Palavras-chave: resiliência; desenvolvimento infantil; fator de proteção; fator de risco.

\section{Resilience and Child Development of Children who Take Care of Children: A Vision in Perspective}

\begin{abstract}
The present study aimed to investigate how girls at risk are dealing with the responsibility of taking care of their younger siblings and home tasks. Four girls, eight to 12 year-old were interviewed. The data were analyzed by lefevrian qualitative method. The results revealed that the situations and the risks that the girls are submitted deflagrate resilience, demonstrating that they can use different ways and resources to face and to overcome their problems and difficulties.
\end{abstract}

Key words: resilience; child development; risk factor; protective factor.

Muitas crianças apresentam problemas em seu desenvolvimento, tanto relacionados à conduta como a desequilíbrio emocional. Tais problemas ocorrem por enfrentamento de eventos estressantes e de risco no seu dia-a-dia. Algumas crianças superam as dificuldades impostas por um ambiente hostil e se desenvolvem dentro de padrões esperados para o seu desenvolvimento, permanecendo na escola, tendo amigos e bom relacionamento familiar. No futuro, serão adultos que encontrarão trabalho e são socialmente competentes e produtivos. Essa forma de lidar com situações difíceis traduziria sua resiliência, pois respondem de modo consistente e positivo aos desafios e às dificuldades, além de reagirem com flexibilidade diante de circunstâncias desfavoráveis, através de uma atitude otimista e perseverante (Tavares, 2001). Para Garmezy (1996), são resilientes, pois a condição de resiliência é definida a partir da compreensão das conseqüências da exposição de adultos e crianças a fatores de risco: alguns poderão desenvolver problemas, outros podem superar as adversidades, adaptando-se ao contexto.

$\mathrm{O}$ crescimento de crianças em situação de pobreza é ressaltado por diversos pesquisadores como uma ameaça ao bem-estar e uma limitação de oportunidades de desenvolvimento (Hutz, Koller \& Bandeira, 1996). A pobreza não é uma variável unitária, mas um conjunto de condições e eventos desfavoráveis que se enlaçam e se acumulam (Kim-Cohen, Moffitt, Caspi \& Taylor, 2004). A UNICEF (2001) postula

1 Endereço: Rua José Martelli 92, Bento Gonçalves, RS, Brasil 95700000. E-mail: mipoletto@ hotmail.com que: "Assim como bem-estar significa mais do que riqueza, pobreza significa mais do que renda insuficiente para cobrir as necessidades mínimas de uma família" (p. 27).

Embora a literatura seja crescente, ainda existem poucos estudos que relacionam a capacidade de resiliência e o desenvolvimento infantil e apresentem conclusões claras. Novas informações têm surgido recentemente e demonstram que nem sempre a criança que cresce em situações desfavoráveis terá uma vida infeliz. O estudo desenvolvido por Alvaréz, Moraes e Rabinovich (1998) pode ser tomado como exemplo. Os autores constataram que crianças, que tiveram longa permanência em orfanatos, apontaram a instituição como norteadora e mediadora de situações de risco na infância. Atribuíram a ela, auxílio na formação de seus comportamentos, podendo representar a função de parentagem, ou seja, o exercício educativo de responsabilizar, dirigir e mostrar o caminho. Esta representação positiva da instituição foi possível, porque favoreceu a essas crianças que utilizassem sua capacidade de resiliência.

$\mathrm{O}$ estudo do desenvolvimento humano, com ênfase nos processos evolutivos saudáveis que caracterizam a resiliência, vem sendo o foco no campo das pesquisas em Psicologia do Desenvolvimento (Carpena, 1999; De Antoni \& Koller, 2000). De acordo com Moraes e Rabinovich (1996), a resiliência é necessária para minimizar os efeitos negativos da adversidade e maximizar habilidades para funcionar no mundo onde ela está inserida, que pode ser potencialmente hostil. Dessa forma, a compreensão do termo resiliência, no desenvolvimento, é parte do entendimento e da prevenção 
de dificuldades psicológicas e de desajustes sociais. Moraes e Rabinovich (1996) salientam que a atenção atual às crianças resilientes existe em função da mudança de foco para a prevenção primária, decorrente de pressões econômicas associadas ao crescimento da demanda por serviços de saúde, principalmente mental e desejo de justiça social.

Originariamente, o termo resiliência surgiu na Física e refere-se à "propriedade pela qual a energia armazenada em um corpo deformado é devolvida quando cessa a tensão causadora da deformação elástica" (Ferreira, 1975, p. 1223). Um exemplo muito utilizado para representar tal conceituação é o de um elástico que, após uma tensão inicial, volta ao mesmo estado. Na Psicologia, a conceituação do termo resiliência não é tão precisa como na Física e na Engenharia, principalmente considerando a multiplicidade e a complexidade de fatores e variáveis que devem ser levados em conta no estudo dos fenômenos humanos. Nos últimos dez anos, este construto tem sido muito discutido, levando os pesquisadores a identificá-lo como amplo, polêmico, dinâmico e em fase de construção (Kim-Cohen \& cols., 2004).

$\mathrm{O}$ enfoque da resiliência está dirigido às situações que visam ao estudo do desenvolvimento humano sadio e positivo. Ao considerar a criança como um ser atuante frente ao ambiente, é tomado o pressuposto de que conseqüentemente, quanto mais resistente às condições desfavoráveis e estressantes, mais ativamente desenvolverá estratégias que a beneficiarão.

Rutter (1987) define resiliência da seguinte maneira:

variação individual em resposta ao risco e que os mesmos estressores podem ser experienciados de maneira diferente por diferentes pessoas. (...) A resiliência não pode ser vista como um atributo fixo do indivíduo, e se as circunstâncias mudam, a resiliência se altera. (p. 317)

Para ele, a resiliência só poderia ser vista como um conjunto de processos sociais e intrapsíquicos que acontece em um dado período, associado a certas combinações benéficas de atributos da criança, de sua família, do ambiente social e cultural. Dessa forma, todos os processos psicossociais que subjazem ao desenvolvimento saudável podem estar envolvidos na resiliência.

A resiliência é considerada por Moraes e Rabinovich (1996) como "uma combinação de fatores que auxiliam os indivíduos a enfrentarem e superarem problemas e adversidades na vida" (p. 11). Apontam pesquisas recentes que enfocam três fontes de resiliência: atributos pessoais, atributos do ambiente e atributos do funcionamento psicológico da criança. Como atributos do ambiente elegem como principal a maternagem competente, que inclui responsividade às necessidades únicas da criança, oportunidade para modelar comportamentos e propiciar o desenvolvimento da criatividade e da expressividade. Uma rede de relações informais, apoio social formal (educação), atividade organizada e fé são outros atributos do ambiente também mencionados. Em relação aos atributos pessoais focalizam: ausência de deficiências orgânicas, temperamento fácil, idade precoce por ocasião do trauma, ausência de perdas e de separações precoces. Conforme Moraes e Rabinovich (1996), as características do funcionamento psicológico da criança resiliente incluem: inteligência e capacidade de resolver problemas, autonomia ou locus interno de controle, elevada auto-estima, empatia, desejo e capacidade de planejamento, e senso de humor.

Rutter (1987) afirma que a resiliência é um processo que relaciona mecanismos de proteção, que não necessariamente eliminam os riscos, mas encorajam a pessoa a se engajar na situação de superação do mesmo efetivamente. Cowan, Cowan e Schulz (1996) também relacionam resiliência a risco: " $r e$ siliência refere-se aos processos que operam na presença de risco para produzir conseqüencias boas ou melhores do que aquelas obtidas na ausência de risco" (p. 14).

Uma criança será considerada em situação de risco quando seu desenvolvimento não ocorrer conforme o esperado para sua faixa etária e para os parâmetros de sua cultura (Hutz \& cols., 1996). Para Tavares (2001), os "fatores de risco relacionam-se com toda a sorte de eventos negativos de vida, e que, quando presentes, aumentam a probabilidade de o indivíduo apresentar problemas físicos, sociais ou emocionais" (p. 24). Um olhar cauteloso e crítico sobre a história da infância demonstra que riscos de todas as espécies de estressores sempre estiveram presentes em qualquer tempo e lugar, o que varia é a construção social do que se constitui como risco (Alves, 2002; Martineau, 1999).

A exposição a fatores de risco pode exacerbar o que a literatura apresenta como condição de vulnerabilidade, contribuindo para a compreensão do que ocorre ao indivíduo em situação de risco (Rutter, 1987). "Se, diante de eventos de risco, um indivíduo desencadeia uma doença, pode ser identificado como vulnerável, porém se consegue dominar a situação através de um comportamento adaptativo positivo, é resiliente" (De Antoni \& Koller, 2000, p. 43). De acordo com Hutz e cols. (1996), todos aqueles elementos que potencializam situações de risco ou impossibilitam que os indivíduos respondam de forma satisfatória ao estresse podem remeter à vulnerabilidade. Fatores de proteção, no entanto, podem ser identificados e ativados na situação de risco. Podem não ter efeito na ausência de um estressor, pois sua função é modificar a resposta do indivíduo em situações adversas, mais do que favorecer diretamente o desenvolvimento. Neste sentido, três aspectos são considerados: 1) um fator de proteção não é necessariamente uma experiência agradável; 2) os fatores protetivos podem não ter efeito algum na ausência de um estressor; e, 3) os fatores de proteção não são somente experiências, mas também as características do indivíduo como pessoa (Rutter, 1987). Garmezy (1996) acrescentou, ainda, que o potencial de proteção deve ser avaliado de acordo com elementos internos e externos do desenvolvimento, considerando outros mecanismos de proteção, como: 1) constância e permanência no cuidado a criança; 2) habilidades para solução de problemas; 3) empatia no relacionamento com amigos e adultos; e, 4) identificação com modelos adultos ou crianças mais velhas e mais competentes. Diante de uma situação estressora, os conceitos de proteção e de vulnerabilidade podem aparecer como se fossem lados diferentes de uma mesma moeda, no entanto, não significa dizer que proteção signifique ausência de vulnerabilidade.

Eckenrode e Gorre (1996) classificam os fatores de proteção em dois grupos: 1) pessoais e 2) recursos do ambiente. Os fatores pessoais evidenciam-se pelas condições biológicas, através da saúde física e do temperamento, e se relacionam às experiências com o ambiente social, através da 
auto-estima e das relações de confiança. O poder aquisitivo ou o apoio social oferecido pela comunidade e a afetividade oportunizada pela família, pelos amigos e pelos demais membros significativos do contexto ecológico, são aspectos ligados aos recursos do ambiente.

O apoio social pode aparecer como um dos determinantes da saúde mental, entretanto Tavares (2001) aponta para a maneira como o apoio social atua como fator de proteção. Considera, assim como Brito e Koller (1999), que é a percepção do suporte social que protege os indivíduos contra a desestabilização. Diante disso, o que realmente importa não é apenas o meio socio-ambiental, mas as significações internas do indivíduo sobre ele.

Hawley e DeHaan (1996) salientam que a família aparece como fator protetivo e como um fator de risco na literatura. Esta aparente ambigüidade é justificada quando se considera a família como um grupo social básico do indivíduo, cuja função e estrutura são determinantes em seu desenvolvimento. As relações entre pais e filhos são caracterizadas por uma enorme complexidade, sendo, então, indispensável a promoção, por parte dos pais ou cuidadores, de um ambiente incentivador, protetivo e seguro, onde a criança possa aprender e se desenvolver. A família protetiva proporciona o alicerce necessário para sua socialização. A existência de cuidado entre irmãos tem sido apontada pela literatura (Luthar \& Zigler, 1991; Pitkeathley \& Emerson, 1998; Werner \& Smith, 1992, 1998; Whittemore \& Beverly, 1989) como fator auxiliar no processo de socialização da criança, especialmente de meninas com relação aos irmãos menores. Uma relação constantemente apontada consiste na condição de resiliência com a interação de irmãos, sugerindo que o relacionamento próximo, de parceria e mútua ajuda entre irmãos aumenta a capacidade da pessoa, na idade adulta, de enfrentar adversidades (Werner \& Smith, 1992). No entanto, há controvérsias com relação ao tipo de relação exigida pelas condições socioeconômicas da família para o desenvolvimento destes. Famílias com baixo nível sócio-econômico, com pais desempregados ou empregados em profissões de status baixo, famílias numerosas e ausência de um dos pais podem exigir que irmãos mais velhos tenham que tomar conta dos mais novos para que ambos pais possam lutar pela sobrevivência do grupo.

Luthar e Zigler (1991) enfatizam que crianças pobres apresentam mais condições de desenvolver-se saudavelmente, mesmo quando têm que cuidar de seus irmãos. Tais casos ocorrem quando os pais apresentam atitudes positivas na educação para o sucesso na vida e estimulam a cooperação entre irmãos. A proximidade com os irmãos propicia, ainda, o apoio emocional, estendendo-se, na vida adulta, em maior competência social e iniciativa no auxílio ao outro. Werner e Smith $(1992,1998)$ observaram, em seus estudos sobre resiliência e vulnerabilidade, que os irmãos mais velhos dispensavam cuidado ao irmão mais novo, e manifestavam esses cuidados mesmo na vida adulta. Observaram ainda, que os irmãos que apresentavam o sistema de cuidados entre si, continuavam contando com seus irmãos sempre que se deparavam com situações emergenciais. Para Werner e Smith $(1992,1998)$, aqueles que rompem antigos vínculos familiares manifestaram tendência a problemas múltiplos, como dificuldades financeiras, maritais, alcoolismo, entre outros, o que reforça a idéia de que uma relação duradoura entre irmãos pode funcionar como fator de proteção frente às adversidades da vida. Alguns grupos sociais enfatizam a participação conjunta dos irmãos nas tarefas domésticas, algumas vezes como forma de organização e sobrevivência, outras como uma preservação das tradições do grupo social e evolução histórica (Weisner, 1989).

A investigação sobre cuidados entre irmãos deve levar em conta, no entanto, os efeitos sobre a criança que cuida e sobre a criança que é cuidada. Lordelo e Carvalho (1999) salienta que a criança que cuida de seus irmãos desenvolve-se socialmente, revelando comportamento pró-social responsável, maior autonomia, melhores estratégias cognitivas, responsabilidade social e treinamento em funções que vai desempenhar ao longo de seu ciclo vital. A criança que cuida de seu irmão pode proporcionar ao que é cuidado a sua visão e descrição da realidade, das tradições e da sociedade na qual estão vivendo. A criança que é cuidada proporciona ao que cuida, uma ocasião para praticar suas habilidades sociais (Whittemore \& Beverly, 1989). No entanto, o cuidado e a responsabilidade exigida à criança pelo cuidado dos irmãos pode representar sobrecarga e pressão exacerbada.

Um estudo brasileiro revelou características de algumas famílias, nas quais a participação dos irmãos mais velhos em atividades domésticas foi considerada essencial para a manutenção da família. Irmãos mais velhos foram descritos como competentes agentes socializadores, capazes de orientar, estimular e facilitar a participação dos irmãos menores nas atividades familiares e comunitárias (Ferreira \& Mettel, 1999). Esse estudo chama a atenção, no entanto, para fatores sociais e econômicos que interferem na dinâmica familiar e nas práticas educativas das crianças.

Bolsoni (2000), em um estudo, investigou a relação entre empatia e o número de irmãos, bem como avaliou se o número de irmãos consistia em um elemento de proteção ou de risco ao desenvolvimento. Observou que crianças que tinham muitos irmãos podiam estar em situação de risco no caso de famílias muito pobres, que dividiam entre tantos filhos os poucos recursos que dispunham. No entanto, o cuidado entre irmãos, mesmo nestas famílias numerosas foi considerado como um fator importante de proteção. Bolsoni (2000) salientou, ainda, que crianças que têm irmãos apresentam maior desenvolvimento emocional e social, especialmente com relação à empatia.

Em um estudo realizado no interior do Rio Grande do Sul, irmãos foram identificados como comportando-se, tanto competitivamente como de forma cooperativa. Os atos de cooperar, dividir, ganhar e perder mostravam modificar pensamentos, expectativas e condutas sociais (Poletto \& Koller, 2001). As brigas são um tipo de interação normal em famílias com irmãos, mas parecem menos freqüentes, quando o número de irmãos é mais reduzido (Bee, 1996). Essas interações que se baseiam em tocar, empurrar, derrubar são atitudes normais entre irmãos, assim como manter contatos físicos como expressões de afeto (carícias, beijos, abraços, etc.) são elementos naturais na maioria das famílias. A convivência com os irmãos permite dividir, mesmo que contra a vontade, objetos e a atenção de pessoas significativas, mas eles também aprendem a colaborar e a reconhecer quem gosta deles (Pitkeathley \& Emerson, 1998). 
O presente estudo visou investigar como meninas pobres estão lidando com a situação de risco de se responsabilizar por irmãos menores, como parte dos cuidados da casa, compreendendo esta atividade à luz do construto de resiliência no desenvolvimento infantil. Foram investigados fatores e processos psicológicos ligados à resiliência, que possam trazer maior clareza sobre o desenvolvimento infantil. São sublinhadas características de risco e de proteção envolvidas, que possam subsidiar intervenções e programas de intervenções junto a grupos que estão sob situações de risco.

\section{Método}

\section{Participantes}

Participaram deste estudo quatro meninas, com idade entre oito e 12 anos, de nível socioeconômico baixo. As meninas permaneciam em casa no período extra-escolar, realizando atividades domésticas e com a responsabilidade de cuidar de irmãos menores. Optou-se por meninas como participantes deste estudo porque elas, socialmente, recebem o legado de desempenhar papéis, comumente esperados da figura feminina, ou seja, cuidar de crianças e realizar atividades domésticas. As características da amostra quanto à idade, série e dados dos pais são apresentadas no Quadro 1.

\section{Instrumentos e procedimentos}

Foi utilizada uma entrevista semi-estruturada, com questões sobre aspectos sócio-demográficos, atividades diárias das crianças, cuidado dos irmãos, seus sentimentos e relacionamentos, e como percebem os acontecimentos em seu cotidiano e em suas vidas. As meninas foram encontradas em um centro de atendimento à criança, de um bairro pobre de Bento Gonçalves (RS), do qual haviam participado anteriormente. Contudo, estavam afastadas para cuidar de seus irmãos em casa, na ausência dos pais. Após apresentação do objetivo do estudo à diretora do centro, a um dos responsáveis pela criança e a ela própria, foi obtida a assinatura ao Termo de Consentimento Livre e Esclarecido. Nas entrevistas, foi utilizado o gravador e, posteriormente, as mesmas foram transcritas literalmente, possibilitando, assim, uma análise mais fidedigna das informações. A duração de cada entrevista foi de aproximadamente 40 minutos e o local para sua realização priorizou o que ficasse mais cômodo para o participante. Dessa forma, duas meninas escolheram o centro de atendimento à criança e duas, a escola.

\section{Resultados e Discussão}

Foram levantados dados sócio-demográficos das meninas participantes que estão apresentadas no Quadro 1. As meninas participantes têm idades entre oito a 12 anos, encontramse regularmente matriculadas entre a terceira série e a sétima série do Ensino Fundamental. Em seguida, foram levantados dados sobre a configuração familiar das meninas, que são apresentados no Quadro 2. Tais informações revelam que todas moram com seus pais e irmãos e que pelo menos um irmão recebe cuidados das meninas participantes.

Para a análise das entrevistas as informações coletadas foram submetidas ao método de pesquisa qualitativa proposto por Lefèvre, Lefèvre e Teixeira (2000), denominado Discurso do Sujeito Coletivo (DSC). A construção do DSC ocorre através da reconstrução das falas de cada participante, com base na análise dos discursos individuais de cada uma das participantes em cada uma das questões.

Foram construídas nove categorias, a partir das respostas às entrevistas: 1) atividades diárias; 2) percepções em relação ao centro comunitário; 3) brinquedos e brincadeiras; 4) relacionamento com a família; 5) figura importante além dos pais; 6) percepções de desejos e necessidades; 7) sentimentos; 8) momentos marcantes positivos e negativos; e, 9) futuro.

Quadro 1. Características sócio-demográficas das meninas participantes e de seus pais e mães

\begin{tabular}{|c|c|c|c|c|c|}
\hline Participante & Características & Patrícia & Gisele & Tatiane & Ana \\
\hline \multirow[t]{3}{*}{ Criança } & idade & 10 anos & 11 anos & 12 anos & 8 anos \\
\hline & escolaridade & $2^{\mathrm{a}}$ série & $7^{\mathrm{a}}$ série & $6^{\mathrm{a}}$ série & $3^{\mathrm{a}}$ série \\
\hline & turno & tarde & tarde & tarde & manhã \\
\hline \multirow[t]{2}{*}{ Pai } & idade & 29 anos & 31 anos & 30 anos & 34 anos \\
\hline & profissão & pintor & metalúrgico & pedreiro & pedreiro \\
\hline \multirow[t]{3}{*}{ Mãe } & idade & 30 anos & 27 anos & 28 anos & 40 anos \\
\hline & profissão & merendeira & faxineira & faxineira & costureira \\
\hline & trabalho & 8h diárias & 8h diárias & manhã & $8 \mathrm{~h}$ diárias \\
\hline
\end{tabular}

Nota: O nome dos participantes é fictício para garantir confidencialidade e proteção da privacidade.

Quadro 2. Configuração familiar das meninas participantes

\begin{tabular}{|c|c|c|c|c|}
\hline Participante & Patrícia & Gisele & Tatiane & Ana \\
\hline $\begin{array}{l}\text { Com quem mora (irmãos } \\
\text { sexo/idade em anos) }\end{array}$ & pais e dois irmãos (or18 e 7) & $\begin{array}{l}\text { pais, avó, tio e três irmãos } \\
\left(\text { ( } 7 \text { e } 4 \sigma^{x} 9\right)\end{array}$ & $\begin{array}{c}\text { mãe, padrasto e quatro } \\
\text { irmãos ( }\left(^{\star} 12,8,5 \text { e } 6 \text { meses }\right)\end{array}$ & pais e uma irmã (ㅇ 5) \\
\hline $\begin{array}{l}\text { Sexo (idade em anos) do } \\
\text { irmão que cuida }\end{array}$ & $o^{\pi}(7)$ & $\begin{array}{c}\text { 우 (4 e 7) } \\
\sigma^{x}(9)\end{array}$ & $\sigma^{\pi}(5)$ & q (5) \\
\hline
\end{tabular}


Com relação à categoria nomeada atividades diárias, as meninas apontaram as atividades desenvolvidas desde o turno da manhã até a noite. Todas as meninas entrevistadas relataram tarefas domésticas, tais como: limpar e arrumar a casa, lavar a roupa, preparar as refeições da família, além de responsabilizarem-se pelos cuidados de seus irmãos menores. Tais atividades confirmam o que foi mencionado por Mello (1999), sobre a necessidade de assumirem tarefas, para auxiliarem suas famílias, porque da sua contribuição depende a sobrevivência da família. As meninas entrevistadas enfatizaram a necessidade de que suas mães contribuam com a renda familiar, por isto vêem-se obrigadas a assumir a responsabilidade de cuidar de irmãos menores e a ajudar na realização de tarefas em casa. Caso não o façam, as meninas verbalizaram que, de alguma maneira, são punidas pela mãe.

Assumem na família tarefas que exigem um papel adulto durante o dia. Tal papel reflete-se em outras atividades do cotidiano, como, por exemplo, assistir "a novela das oito" na televisão. Tal atitude pode revelar a expectativa irrealistíca destas famílias com relação às meninas. Postman (1999) afirma que as crianças presenciam cenas de nudez, sexo, violência e se apropriam do vocabulário do adulto, tendo um contato com o mundo adulto que desde a Idade Média não tiveram. Apesar dos canais televisivos anunciarem, na apresentação de programas à noite, que esse não é apropriado para crianças menores de 14 anos, parece que os pais não demonstram estarem atentos aos riscos a que suas filhas estão expostas por assistirem a tais programas, assim como exigem delas que tenham outras responsabilidades com seus irmãos menores.

Outra atividade diária expressa pelas meninas, consiste em ir à escola. As meninas entrevistadas não atribuem aspectos negativos à escola, mostrando-se satisfeitas com tudo, mas mencionam que em algumas matérias poderiam se desenvolver melhor. A escola tem sido apontada como uma influência significativa no desenvolvimento infantil, podendo tanto potencializar o risco como proteger a criança (Hutz \& cols., 1996). Por isto, é importante quando a escola também é um espaço visto pelas meninas como lúdico, no qual podem interagir e brincar com outras crianças, principalmente na hora do recreio. Esse sentimento positivo relacionado à escola pode ser considerado um fator de proteção, já que, ao oportunizar algumas intervenções, a escola auxilia no desenvolvimento de habilidades. É possível que durante o período escolar, como mencionam Pedro-Carrol e Cowen (1985), este contexto facilite e auxilie as meninas a lidar com o estresse vivido, reduza comportamentos de risco e, conseqüentemente, potencialize sua capacidade de resiliência. Tais vivências escolares positivas na vida dessas meninas repetem o que foi apontado por Rutter (1987), que observou crianças de famílias de nível sócio-econômico muito baixo que conseguiam planejar suas vidas, mesmo quando experienciavam este tipo de vivência na escola.

A categoria nomeada percepções em relação a uma das instituições da rede de apoio refere-se especificamente à maneira como as meninas entrevistadas percebem o centro de atendimento à criança que freqüentavam. Todas demonstraram gostar das atividades oferecidas, principalmente das atividades de recreação em que podiam brincar em grupo e que envolvessem a mobilidade corporal. Elas se referem ao centro como um ambiente familiar, no qual realizam atividades como se estivessem em casa, brincam, lancham, têm atividades externas no pátio. Apesar de todas as meninas entrevistadas relatarem gostar das atividades propostas no centro, algumas traduzem em suas falas a queixa de que deixaram de freqüentá-lo por precisarem cuidar de irmãos e realizarem tarefas em casa. Importante considerar que o fato das meninas deixarem de freqüientar o centro pode configurarse uma situação de risco, já que tal espaço propicia a vivência, a aprendizagem e o reforço das habilidades e das capacidades sociais e emocionais principais para o desenvolvimento. Esta instituição configura-se como parte de uma rede de apoio que pode estar funcionando como fator de proteção. Ao se levar em conta o que foi mencionado por Tavares (2001) e Brito e Koller (1999) sobre a significação que o indivíduo atribui à rede de apoio ser mais importante do que a rede em si, considera-se fundamental que haja possibilidade de revisão desta saída do centro de atendimento pelas meninas.

A terceira categoria foi nomeada brinquedos e brincadeiras. Nas falas de meninas, o momento de brincar não parece ocupar muito do tempo, limita-se a um ínfimo espaço físico e só pode ocorrer depois de realizadas as obrigações com os irmãos e a casa. Diante da significativa importância da brincadeira para a criança, a dificuldade em dispor de momentos para o lúdico pode ser pensada como um fator de risco a que estas meninas estão expostas, pois é nesse espaço que a criança compreende o que acontece ao seu redor, como o mundo funciona e pode elaborar e aprender com as situações e dificuldades que experiencia (Santos \& Koller, 2003). A brincadeira, conforme afirma Winnicott (1982), "fornece uma organização para a iniciação de relações emocionais e assim propicia o desenvolvimento de contatos sociais" (p. 163). No entanto, quando a verbalização sobre os brinquedos e brincadeiras aparece, difere significativamente do que ocorreu anteriormente. A brincadeira mostra-se bastante intensa neste momento da vida e em todos os espaços freqüentados, tanto na escola como em casa. Além disso, através do que descrevem, demonstram criar brincadeiras com os mais variados objetos: "eu vou pra uma laje que tem lá fora e pegava travesseiro, guarda-chuva, brinquedo, coberta, cobertor, boneca, um monte de coisa e ficava brincando" (Ana, 8 anos). Winnicott (1982) afirma que "as crianças são capazes de encontrar objetos e inventar brincadeiras com muita facilidade e isso lhes dá prazer" (p. 161).

A necessidade de suas famílias e a pressão exercida pela mãe coloca essas meninas em uma situação sem escolha. Seu tempo para brincadeiras é reduzido, não freqüentam mais o centro de atendimento à criança, onde há um espaço de recreação do bairro. Dedicam grande parte do seu tempo às atividades da casa e ao cuidado de seus irmãos menores, mas ainda assim, percebem sua vida como cheia de brincadeira. Mesmo não gostando de realizar algumas tarefas em casa, conseguem tempo para brincar e estudar em casa à tarde, pois "de noite é difícil e eu não consigo, senão de manhã ninguém me tira da cama de sono" (Ana, 8 anos). Esta fala parece demonstrar que essa menina está atenta às suas necessidades e, de como, para ela, as atividades podem ser realizadas da melhor maneira. Tal comportamento pode estar ligado a um dos importantes fatores relacionados a resiliência, o sentimento de auto-eficácia definido por Bandura (1989), como 
a crença da pessoa sobre sua capacidade de desempenho em atividades específicas, envolvendo o julgamento sobre suas capacidades, para a mobilização de recursos cognitivos e ações de controle sobre eventos e demandas do meio.

A quarta categoria, nomeada relacionamento com a família nuclear, refere-se à qualidade da relação das meninas com os integrantes de sua família. Percebe-se, através das falas das meninas, a significativa importância que elas atribuem às suas famílias. É na família que buscam afeto e continência, apesar desta nem sempre responder às suas necessidades. Nas verbalizações das meninas, a relação com o pai parece ser distante, pouco afetuosa e com certa idealização. Diante disso, é importante sublinhar que "a privação de afeto significa uma ameaça de rompimento de um forte laço emocional entre os pais e a criança, gerando insegurança e ansiedade" (Reppold, Pacheco, Bardagi \& Hutz, 2002, p. 16). A maioria das meninas fala muito brevemente sobre o pai e não traz muitos elementos da relação com ele, limitando-se a responder o que foi questionado de maneira sucinta. $\mathrm{O}$ oferecimento de objetos materiais, para algumas meninas, parece ser percebido como uma forma de o pai lhe oferecer carinho. Apenas uma menina verbaliza: "gosto do meu pai porque ele me dá carinho" (Gisele, 11 anos), entretanto em nenhum momento durante a entrevista esta menina relata algum evento no qual o pai tenha sido carinhoso com ela. Apesar da relação ser distante e pouco afetuosa, a fala das meninas, quando se referem ao pai, possui certa amabilidade, o que revela estas meninas entendem que a relação com o pai é "naturalmente" dessa maneira e parecem não esperar manifestações dele muito diferentes das que já conhecem.

Ligado às questões de afeto relacionadas ao pai, aparece a idealização, como exemplifica a fala a seguir: "lá em casa, nós moramos junto com a minha vó, o meu tio que mora junto e não trabalha e, daí é só o meu pai que sustenta e, é dificil pro meu pai e ele tem mais conta" (Gisele, 11 anos). Essa justificação parece uma idealização da figura paterna, uma vez que a menina aponta apenas o pai como provedor da família, embora a mãe também contribua no sustento da casa. Estas meninas expressam o que Bradt (1995) aponta como a típica noção de um bom pai, que está ligada ao pai que trabalha e sustenta a esposa e os filhos. A importância do pai, afetuoso e envolvido com os filhos, que também é enfatizada por Bradt (1995), aparece na expressão de afeto de uma das meninas ao homem que lhe acolheu como filha legítima: "é que eu não sou filha verdadeira dele, só que ele colocou lá no papel o nome dele como meu pai" (Tatiane, 12 anos). Através dessa fala, essa menina parece sentir-se muito grata por ter sido acolhida como filha.

Outro aspecto que aparece na entrevista das meninas, com relação à família nuclear é a presença de alcoolismo na família. Um dos efeitos mais trágicos do alcoolismo paterno nas crianças pequenas é que ele rouba a sua infância, principalmente porque quando um dos progenitores é alcoolista, este distorce os processos e os papéis familiares. Para Krestan e Bepko (1995), quando há alcoolismo entre seus membros, a família já não consegue desempenhar uma de suas funções primordiais, que é garantir a segurança emocional e física da criança. A situação acima elencada, exemplifica a realidade vivida por muitas crianças, submetidas a um ambiente familiar no qual desconfiança, culpa e tristeza têm presença marcante, especialmente nas situações de conflito que provoca.

A relação das meninas com a mãe demonstra ser mais próxima do que a relação com o pai, mesmo quando este aparece idealizado (De Antoni, 2000). A mãe manifesta mais carinho que o pai e a ela, as meninas, recorrem, quando algo não vai bem. Este fato confirma o que Barnard (1994) identifica como importante: tanto o relacionamento produtivo com a figura materna como um dos elementos básicos na promoção da resiliência. Para algumas meninas, a figura materna assemelha-se a um porto seguro, apesar deste porto, às vezes, mostrar-se vulnerável e pouco receptivo pelas condições de vida. A preocupação com o bem-estar das mães também está presente na fala das meninas, " $e u$ volto da escola aí eu recolho a roupa depois eu dobro e daí quando minha mãe chega em casa cansada ela não precisa fazer" (Patrícia, 10 anos).

A maioria das meninas não aponta aspectos negativos relacionados à mãe. Apenas verbalizam que não gostam quando a mãe bate nos irmãos e quando desconta a raiva que sente nos filhos por brigar com o companheiro. Desse último aspecto, considera-se importante a percepção que esta menina sente da reação da mãe, quando ela diz: "quando ela fica, assim, braba, daí ela discute com a gente quando ela briga com meu pai, né daí ela fica com raiva e desconta em nós" (Gisele, 11 anos). Neste sentido, demonstra perceber que apesar da mãe talvez se irritar com a menina e seus irmãos, muitas vezes, essa irritação advém da discussão que esta teve com seu companheiro. A menina poderia absorver todo sentimento transmitido pela mãe de maneira totalmente negativa, no entanto pelo entendimento que ela dá ao comportamento da mãe, demonstra utilizar seus recursos internos para compreender o que está ocorrendo. A resposta, diante dessas situações com a mãe, faz pensar que esta menina consegue dar conta dessa demanda, o que pode estar relacionado a resiliência. Chama a atenção, no entanto, que as meninas tenham uma atitude de cuidado e proteção aos irmãos, assumindo o papel de cuidadoras dos mesmos, também na presença da mãe e para protegê-los dela nas horas de conflito. As meninas ao verbalizarem desaprovação quando os pais batem em seus irmãos parecem assumir aspectos cuidadores e protetivos relacionados a eles.

A interação das meninas com os irmãos parece bastante intensa. A maioria delas demonstrou sentir-se bem na companhia dos irmãos e com eles compartilhar momentos de brincadeira. Apresentam demonstrações afetivas, nas quais estão presentes aprendizados, trocas e apoio mútuo, representando o que Minuchin (1982) chamou de primeiro laboratório social, no qual o relacionamento fraternal permite que as crianças possam experienciar relações com iguais. Algumas meninas verbalizaram que gostam de cuidar de seus irmãos menores. Mencionaram também conflitos, que são qualificados como negativos e causadores de tristeza. Este laboratório social - relação fraternal - também necessita da presença de conflitos, desavenças e sentimentos hostis. Diante disso, pode-se convergir o entendimento deste aspecto de dois vértices. $\mathrm{O}$ primeiro considera que as meninas aprendem a cuidar, perceber e reconhecer as reações e as necessidades de seus irmãos e lhes oferecem cuidados maternais. Sendo a irmã mais velha, como afirma Silveira (2002), a menina 
costuma valorizar mais seus irmãos, assumindo papéis como ensinar e cuidar, mais freqüentemente do que os meninos. No entanto, o segundo vértice leva a crer que estas meninas abraçam uma responsabilidade que nem sempre estão preparadas a assumir, pois, muitas vezes, elas também estão necessitando de cuidados.

A quinta categoria, nomeada figura importante além dos pais, refere-se às pessoas que as meninas sentem como mais próximas a elas além de sua família nuclear. Estas pessoas, em geral, são modelos importantes de sua rede de apoio social, com quem estabelecem relações de reciprocidade e afeto e com quem podem contar em momentos de necessidade. Figuras importantes na vida de várias meninas foram as tias e/ou as primas de idade próxima. As tias aparecem como provedoras e supridoras de necessidades materiais, e também como figuras afetuosas, próximas e acolhedoras, além de proporcionarem oportunidades de crescimento e de novos aprendizados. A presença de uma tia, como figura, mesmo não permanentemente presente, mas freqüente, estável e responsiva na vida da criança, conforme apontado por Fonagy, Steele, Steele, Higgitt e Target (1994), pode ser considerada um fator protetivo. Conseqüentemente, a relação com esta favorece o estabelecimento de um modelo interno mais seguro de apego. Para essas meninas, as tias e as primas realizam esta função. As primas com idade próxima compartilham espaços e experiência de cooperação e amizade. Tais primas representam muitas vezes a irmã mais velha que não tem e com quem podem compartilhar suas inquietações e segredos. Com a prima, também estabelecem uma relação de rivalidade, pois os irmãos cuidados por ela não se prestam a este papel.

A sexta categoria, nomeada percepções de desejos e necessidades, refere-se às necessidades materiais que aparecem fortemente nas falas de todas as meninas. Este aspecto poderia ser previsível dada a situação econômica de suas famílias. Elas gostariam que suas famílias tivessem uma casa melhor e um carro para facilitar os deslocamentos dos pais. As meninas revelam, também, querer auxiliar os pais na manutenção da família. Uma das meninas, embora reconheça as necessidades materiais da família, desejando saná-las, não deixa de querer algo para si como uma festa de aniversário, roupas e calçados. Tal fato demonstra que ela se permite pedir algo para si. A falta de percepção de sua condição de criança que não pode resolver a situação de pobreza pode ser um fator que expõe a criança a situações de risco, buscando atividades que são remuneradas fora de casa. Tal busca pode levá-las à exploração do trabalho infantil e, em um caso extremo, sexual. Este fato revela a situação de vulnerabilidade da criança e da família e o risco latente que a pobreza evidencia na vida destas pessoas.

Um dos desejos manifestados pelas meninas foi pela união da família. A volta dos pais separados, embora o divórcio dos pais não possa ser considerado um fator de risco para os filhos, deve ser contextualizado na vida desta crianças. No caso de famílias separadas por eventos estressantes, a baixa freqüência de risco permanente de violência e uso de drogas pode ser mais protetivo para o desenvolvimento. Este fato é revelado no desejo manifesto de que um dos pais pare de beber. $\mathrm{O}$ alcoolismo é um elemento trazido por duas das meninas entrevistadas, e presente na vida de muitas crianças.
Tal aspecto denuncia uma realidade cruel vivenciada por essas meninas que provoca um amadurecimento precoce, se comparado ao esperado nesta idade.

A sétima categoria, nomeada sentimentos da criança revelou-se pelo medo de fenômenos da natureza e da violência. Tal medo expõe a necessidade de serem cuidadas e protegidas. $\mathrm{O}$ temor de que alguém cause algum mal à integridade pessoal aparece também, e que pode estar representando que, apesar de buscar refúgio com a mãe quando sente medo, nem sempre esta parece conseguir protegê-la. A menina, que traz este medo, revela a presença de violência na comunidade onde vive, caracterizando uma situação muito presente, principalmente em bairros menos seguros: "tenho medo de um cara lá que intica com os outros e leva a gente lá pro mato" (Patrícia, 10 anos). Ela demonstra sentir-se desprotegida e vulnerável diante das situações às quais está exposta, caracterizando tal situação como um fator de risco presente no ambiente. Aparece, ainda, o medo diante da violência intrafamiliar, "tenho medo que meu pai vá lá em casa, porque estes dias ele ameaçou matar minha mãe" (Tatiane, 12 anos). Esta menina sente que precisa dar força, proteger e ajudar a mãe diante das ameaças e agressões do pai, apesar de sentir-se impotente e insegura diante destas ameaças. As meninas vivem em ambientes no qual a violência é um elemento presente, do qual elas têm medo, mas expressam ter consciência deste fenômeno e conseguem verbalizar o medo sentido.

Os momentos de conflitos e brigas com irmãos e as discussões entre os pais foram situações expressadas pelas meninas como causadoras de tristeza. Parece que estas situações trazem tensão, insegurança e desconforto para as meninas e que em muitos momentos não sabem lidar muito bem com isso. A literatura (Cowan \& cols., 1996; Hutz \& cols., 1996; Yunes, 2001) aponta que as ocorrências frequientes de momentos de tensão são consideradas eventos estressores. $\mathrm{Na}$ vida destas meninas, o medo e a tristeza associados aos eventos de violência configuram-se como fatores de risco e provocam a vulnerabilidade no desenvolvimento, podendo levar a uma patologia ou a um distúrbio físico e emocional.

Quando perguntadas sobre o que fazem quando presenciam situações estressantes, as meninas responderam que procuram a mãe. Este fato revela que precisam do acolhimento de um adulto próximo, nesse caso da mãe. Outras tentam por elas próprias fazer algo que as deixe melhor quando algo de desagradável ocorre, "quando fico triste tento melhorar" (Gisele, 11 anos). Esta menina demonstra buscar seus recursos internos para compreender as situações em que está envolvida, neste sentido tal iniciativa pode ser identificada como um sinal de certa autonomia para dar conta de seu estado emocional e talvez da utilização da capacidade de resiliência.

Apenas uma das meninas não demonstrou uma ação "produtiva" quando algo de ruim lhe acontece. Verbaliza "quando acontece algo de ruim desconto tudo em cima da minha irmã" (Ana, 8 anos). Talvez tal comportamento, associado ao medo de tempestades (quando se esconde debaixo das cobertas), pode estar ligado ao simples fato de ser ainda muito pequena.

Quanto ao sentimento de felicidade, as meninas relacionam aos momentos de brincadeira com os irmãos, de ganhar presentes e de participar em eventos de lazer. As respostas, no 
entanto, não foram eloqüentes. Todas elas limitaram-se a um evento que as deixava feliz e uma delas chegou a verbalizar: "pergunta difícil!" (Tatiane, 12 anos).

A oitava categoria diz respeito aos momentos marcantes positivos e negativos, que se referem às vivências de momentos bons e ruins na vida das meninas. Na fala das meninas, os bons momentos apontados diferem significativamente. Uma delas afirma que nada de bom lhe ocorreu, mas informa que o seu melhor momento foi a prisão do irmão, que ao mesmo tempo em que a deixou triste, diminui a situação de conflito na família. Outra menina parece conseguir resgatar mais facilmente os fatos positivos e negativos que ocorreram em sua vida, relaciona a morte dos avós ao pior momento de sua vida. Demonstrou, também, emoção positiva relacionada ao nascimento de sua irmã e o caracteriza como o melhor evento que lhe ocorreu. Nas verbalizações das meninas, aparece a relação com os irmãos, como momentos bons e agradáveis, com cooperação e afeto. Os momentos marcantes de suas vidas, geralmente, estão ligados a eventos dos quais irmãos e pais estão presentes.

A nona e última categoria, nomeada como futuro, referese ao que as meninas imaginam e projetam para o seu futuro e quais as estratégias pensadas por elas para alcançar o que desejam. Direcionam, em geral, desejos para suas famílias, e a realização de sonho de meninas, como conhecer um grupo de garotas famosas na mídia. As meninas fazem projeções importantes e significativas de suas vidas, referindo-se aos estudos e ao trabalho. Apenas uma delas menciona a constituição de uma família, demonstrando ter perspectivas claras do desejo de ser feliz e a isso tem relacionado o casamento e a maternidade.

O aspecto profissional apareceu como possibilidade de êxito no que as meninas desejam realizar. Tal concepção pode representar certa mudança na delimitação atual das atividades e funções atribuídas à mulher. Embora concordem sobre a necessidade de a mulher também contribuir com as despesas da família, as meninas querem no futuro uma ocupação além dos afazeres e responsabilidades domésticos, como fonte de realização.

A partir das informações levantadas, conforme os objetivos deste trabalho, as participantes desse estudo demonstraram ter clareza da realidade da qual fazem parte e estão inseridas. Percebem, também, as necessidades econômicas de suas famílias e as limitações que tal condição implica. As situações abordadas neste trabalho em que as meninas estão envolvidas, principalmente os riscos a que estão submetidas, forçam um amadurecimento antecipado comparado a outras crianças da mesma idade que não vivenciam os eventos retratados. Tais eventos exigem posicionamentos e demandas que obrigam estas meninas a buscarem recursos para dar conta do que se apresenta a elas. Nestes aspectos, a resiliência aparece e, certamente, contribui no enfrentamento e na superação de problemas e adversidades. A família, apesar da condição de risco, continua sendo seu referencial e nela buscam carinho e continência. Da mesma forma, a relação com os irmãos parece ser saudável, embora tire delas muitas vezes a condição de criança. São companheiros, brincam juntos e possibilitam que estas meninas expressem sua capacidade de cuidadora.

Apesar destas meninas demonstrarem dar conta das demandas vividas, os riscos a que estão expostas são graves e constantes e nem sempre estas possuem apoio e recursos suficientes para lidarem com eles. Muitas situações causam dano psicológico e/ou emocional. A resiliência não está presente todo tempo e a cada evento, pois não é um atributo fixo do indivíduo. Se as circunstâncias sofrem alterações, a resiliência se altera, ou seja, estas meninas podem estar lidando bem com as situações difíceis que estão enfrentando no momento, o que não quer dizer que elas apresentem resiliência todo o tempo e em todas as áreas e para sempre.

A escola e o centro de atendimento à criança são importantes referências que favorecem o desenvolvimento de suas habilidades, facilitando a maneira como lidam com as situações vivenciadas. Auxiliam como fontes de recursos na promoção de um ambiente no qual realizar as atividades próprias de uma criança é tarefa principal. Constituindo a rede de apoio social - escola e centro - propiciam que as crianças possam receber e trocar afeto, viver sua infância, amenizando de certa forma angústias e ansiedades. Favorecem a busca de alternativas para as dificuldades e perspectivas para o futuro. Todos estes elementos, diante do que a literatura trata sobre essa temática, contribuem para a potencialização da capacidade de resiliência.

\section{Considerações Finais}

A partir desse estudo, evidencia-se a necessidade de ampliar as investigações sobre os processos e fatores psicológicos e sociais que protegem crianças pobres que tomam conta de casa e de irmãos sozinhas e as tornam menos vulneráveis ao estresse da vida cotidiana. Estas poderão, além de fornecer contribuições ao estudo da resiliência, propiciar e embasar conhecimentos capazes de subsidiar intervenções preventivas e educativas com o propósito de potencializar a capacidade de resiliência e melhorar sua qualidade de vida, principalmente de grupos que vivem em situação de extrema pobreza.

Foi possível perceber que estas meninas demonstram que, diante da necessidade de abraçar certas responsabilidades, também conseguem garantir algum espaço para sonhar, desejar, fazer planos para seu futuro, expressar sentimentos e, principalmente, ter esperança. Diante disso, a implementação de programas de intervenção junto a estes grupos de crianças em situação de risco pode potencializar e favorecer o desenvolvimento da resiliência. Estas meninas apresentam esta capacidade, pois mostraram estar construindo um caminho pelo qual buscam direcionar suas vidas, com a sensação de estarem colocando os pés em solo resistente, através da percepção da realidade da qual fazem parte e estão inseridas, e com perspectivas de chegar a algum lugar no futuro onde possam alcançar seus sonhos. A resiliência rompe com uma noção na qual o indivíduo se vê aprisionado a um ciclo sem saída. Entretanto, a resiliência não é uma saída mágica, o que se apresenta é um novo olhar em relação às crianças que vivem em situações adversas.

\section{Referências}

Alvarez, A. S., Moraes, M. C. L. \& Rabinovich, E. P. (1998). Resiliência: Um estudo com brasileiros institucionalizados. Revista Brasileira de Crescimento e Desenvolvimento Humano, 8(1/2), 70-75. 
Alves, P. (2002). Infância, tempo e atividades cotidianas de crianças em situação de rua: As contribuições da teoria dos sistemas ecológicos. Tese de Doutorado, Universidade Federal do Rio Grande do Sul, Porto Alegre.

Bandura, A. (1989). Human agency in social cognitive theory. American Psychologist, 44, 1175-1184.

Barnard, C. P. (1994). Resiliency: A shift in our perception? American Journal of Family Therapy, 22, 135-144.

Bee, H. (1996). A criança em desenvolvimento. Porto Alegre: Artes Médicas.

Bolsoni, J. (2000). Interação entre irmãos: Empatia e fatores de risco e proteção. Dissertação de Mestrado, Universidade Federal do Rio Grande do Sul, Porto Alegre.

Bradt, J. O. (1995). Tornando-se pais: Famílias com filhos pequenos. Em B. Carter \& M. McGoldrick (Orgs.), As mudanças no ciclo da vida familiar: Uma estrutura para a terapia familiar (pp. 206-222). Porto Alegre: Artes Médicas.

Brito, R. C. \& Koller, S. H. (1999). Desenvolvimento humano e redes de apoio social e afetivo. Em A. M. A. Carvalho (Org.), O mundo social da criança: Natureza e cultura em ação (pp. 115-126). São Paulo: Casa do Psicólogo.

Carpena, M. E. F. (1999). Família de meninos em situação de rua na cidade de Caxias do Sul: Locus de controle, situação atual de vida e expectativas para o futuro. Dissertação de Mestrado, Universidade Federal do Rio Grande do Sul, Porto Alegre.

Cowan, P. A., Cowan, C. P. \& Schulz, M. S. (1996). Thinking about risk and a resilience in families. Em E. M. Hetherington \& E. A. Blechman (Orgs.), Stress, coping and a resiliency in children and families (pp. 1-38). New Jersey: Lawrence Erlbaum.

De Antoni, C. (2000). Vulnerabilidade e resiliência familiar na visão de adolescentes maltratadas. Dissertação de Mestrado, Universidade Federal do Rio Grande do Sul, Porto Alegre.

De Antoni, C. \& Koller, S. H. (2000). Vulnerabilidade e resiliência familiar: Um estudo com adolescentes que sofreram maus tratos intrafamiliares. Psico, 31(1), 39-66.

Eckenrode, J. \& Gore, S. (1996). Context and process in research on risk and resilience. Em N. Garmezy, R. J. Haggerty, M. Rutter \& L. Sherrod (Orgs.), Stress, risk and and resilience in children and adolescents (pp. 19-63). Cambridge: Cambridge University Press.

Ferreira, A. B. de H. (1975). Novo Aurélio: O dicionário do século XXI. São Paulo: Nova Fronteira.

Ferreira, E. A. P. \& Mettel, T. P. (1999). Interação entre irmãos em situação de cuidados formais. Psicologia: Reflexão e Crítica, 12(1), 133-146.

Fonagy, P., Steele, M., Steele, H., Higgitt, A. \& Target, M. (1994). The Emanuel Miller memorial lecture 1992. The theory and practice of resilience. Journal Child Psychology and Psychiatry, 35(2), 231-257.

Garmezy, N. (1996). Reflections and commentary on risk, resilience and development. Em R. Haggerty, L. Scherrod, N. Garmezy $\&$ M. Rutter (Orgs.), Stress, risk and resilience in children and adolescents: Processes, mechanisms and interventions (pp. 1-18). Cambridge: Cambridge University Press.

Hawley, D. \& DeHaan, L. (1996). Toward a definition of family resilience: Integrating life span and family. Family Process, 35, 283-298.

Hutz, C. S., Koller, S. H. \& Bandeira, D. R. (1996). Resiliência e vulnerabilidade em crianças em situação de risco. Coletâneas da ANPEPP, 1(12), 79-86.
Kim-Cohen, J., Moffitt, T. E., Caspi, A. \& Taylor, A. (2004). Genetic and environmental processes in young children's resilience and vulnerability to socioeconomic deprivation. Child Development, 75, 651-668.

Krestan, J. \& Bepko, C. (1995). Problemas de alcoolismo e o ciclo de vida familiar. Em B. Carter \& M. McGoldrick (Orgs.), As mudanças no ciclo da vida familiar: Uma estrutura para a terapia familiar (pp. 415-439). Porto Alegre: Artes Médicas.

Lefèvre, F., Lefèvre, A. M. C. \& Teixeira, J. J. V. (2000). O discurso do sujeito coletivo: Uma nova abordagem metodológica em pesquisa qualitativa. Caxias do Sul: EDUCS.

Luthar, S. S. \& Zigler, E. (1991). Vulnerability and competence: A review of research on resilience in childhood. American Journal Orthopsychiatry, 61, 6-22.

Lordelo, E. R. \& Carvalho, A. M. A. (1999). Um estudo naturalístico sobre comportamento de cuidado entre crianças pré-escolares. Biotemas, 12(1), 7-30.

Martineau, S. (1999). Rewriting resilience: A critical discourse analysis of childhood resilience and the politics of teaching resilience to "kids at risk". Tese de Doutorado, University of British Columbia, Vancouver, Canadá.

Mello, S. L. (1999). Estatuto da criança e do adolescente: É possível torná-lo uma realidade psicológica? Psicologia USP, 10, 139-151.

Minuchin, S. (1982). Família: Funcionamento e tratamento. Porto Alegre: Artes Médicas.

Moraes, M. C. L. de \& Rabinovich, E. P. (1996). Resiliência: Uma discussão introdutória. Revista Brasileira de Crescimento $e$ Desenvolvimento Humano, 6(1/2), 70-75.

Pedro-Carrol, J. L. \& Cowen, E. L. (1985). The children of divorce intervention project: An investigation of the efficacy of a schoolbased prevention program. Journal of Consulting and Clinical Psychology, 53, 603-611.

Pitkeathley, J. \& Emerson, D. (1998). Only child, how to survive being one. Londres: Souvenir Press.

Poletto, R. \& Koller, S. H. (2002). Rede de apoio social e afetivo de crianças em situação de pobreza. Psico, 33(1), 151-176.

Postman, N. (1999). O desaparecimento da infância. Rio de Janeiro: Graphia.

Reppold, C. T., Pacheco, J., Bardagi, M. \& Hutz, C. S. (2002). Prevenção de problemas de comportamento e o desenvolvimento de competências psicossociais em crianças e adolescentes: Uma análise das práticas educativas e dos estilos parentais. Em C. S. Hutz (Org.), Situações de risco e vulnerabilidade na infância e na adolescência: aspectos teóricos e estratégias de intervenção (pp. 9-51). São Paulo: Casa do Psicólogo.

Rutter, M. (1987). Psychosocial resilience and protective mechanisms. American Journal of Orthopsychiatry, 57(3), 316-331.

Santos, E. C. \& Koller, S. H. (2003). Brincando na rua. Em A. M. A. Carvalho, C. M. C. Magalhães, F. A. R. Pontes \& I. D. Bichara (Orgs.), Brincadeira e cultura: Viajando pelo Brasil que brinca (pp. 187-206). São Paulo: Casa do Psicólogo.

Silveira, L. M. (2002). O relacionamento fraterno e suas características ao longo do ciclo vital da família. Em A. Wagner (Org.), Família em cena: Tramas, dramas e transformações (pp. 93-112). Petrópolis: Vozes.

Tavares, J. (Org.). (2001). Resiliência e educação. São Paulo: Cortez.

UNICEF (2001). Situação da infância brasileira. São Paulo: B\&C Revisão de Textos. 
Weisner, T. S. (1989). Comparing sibling relationships across cultures. Em P. G. Zukow (Org.), Sibling interaction across cultures: Theoretical methodological issues. New York: Spring-Verlag.

Werner, E. \& Smith, R. (1992). Overcoming the odds: High risk children from birth to adulthood. New York: Cornell University Press.

Werner, E. \& Smith, R. (1998). Vulnerable but invincible: A longitudinal study of resilient children and youth. New York: McGraw Hill.

Whittemore, R. D. \& Beverly, E. (1989). Trust in mandinka way: The cultural context of sibling care. Em P. G. Zukow (Org.), Sibling interaction across cultures: Theoretical methodological issues. New York: Spring-Verlag.
Winnicott, D. W. (1982). A criança e o seu mundo. (6 ${ }^{\mathrm{a}}$. ed). Rio de Janeiro: LTC.

Yunes, M. A. M. (2001). A questão triplamente controvertida da resiliência em famílias de baixa renda. Tese de Doutorado, Pontifícia Universidade Católica de São Paulo, São Paulo.

Recebido em 15.07.2004

Primeira decisão editorial em 25.10.2004

Versão final em 02.11.2004

Aceito em 22.11.2004 